Bull. Mater. Sci., Vol. 2, Number 4, November 1980, pp. 233-237. (C Printed in India.

\title{
Development of a roller quenching apparatus for the production of amorphous phases
}

\author{
S T LAKSHMIKUMAR, $R$ M MALLYA* and E S R GOPAL \\ Department of Physics, Indian Institute of Science, Bangalore 560 012, India \\ * Department of Metallurgy
}

MS received 2 June 1980

\begin{abstract}
The details of an apparatus designed to produce amorphous phases by rapid quenching from the melt are described. A drop of molten material is squeezed between two copper rollers rotating against each other at 5000 RPM and a thin foil of the material is produced. The system produces cooling rates of the order of $10^{5} \mathrm{~K} / \mathrm{sec}$. Details of the development and construction are mentioned.
\end{abstract}

Keywords. Amorphous phases; quenching; twin rollers.

\section{Introduction}

Amorphous phases in appreciable quantities are generally produced by rapid quenching from the melt or the vapour. Rapid quenching from the liquid phase is achieved by bringing the molten material into sudden contact with a substrate of high thermal conductivity. This is achieved in practice by (i) the Duwez Gun (Duwez and Willens 1963), (ii) the piston and anvil systems (Pietrokowsky 1963), (iii) the roller quenching apparatus (Chen and Miller 1970) and (iv) the melt spinning technique (Pond et al 1969).

Generally the cooling rates produced in the various types of apparatus are about $10^{5}-10^{8} \mathrm{~K} / \mathrm{sec}$. If the quenching is done by introducing the molten material into a cooled liquid, the cooling rate is about $10^{2} \mathrm{~K} / \mathrm{sec}$ because the gaseous film, formed between the liquid and the material, makes the removal of heat from the sample difficult.

The roller and the piston-anvil systems are twin substrate techniques where heat is removed from both surfaces of the sample, which is produced as a thin foil of $10-100 \mu \mathrm{m}$ thickness. In the Duwez gun and melt spinning systems only one substrate is used and heat is removed from one side of the foil.

We have developed a rollar quenching apparatus for generating cooling rates of the order of $10^{5} \mathrm{~K} / \mathrm{sec}$. Essentially the apparatus consists of two copper rollers rotating against each other at about $5000 \mathrm{RPM}$. The molten material is introduced between them and quenched into a thin foil of $50-100 \mu \mathrm{m}$ thickness. We have produced amorphous phases in the $\mathrm{In}-\mathrm{Te}$ and $\mathrm{Cu}-\mathrm{Au}-\mathrm{Te}$ systems. These materials have been previously produced by Duwez gun technique (Takayama 1976). 


\section{Description of apparatus}

The basic arrangement consists of two copper rollers, about $5 \mathrm{~cm}$ in diameter, which are rotated in opposite directions at about 5000 RPM. The details are shown in figure 1. Both the rollers are mounted on ball bearings capable of rotating at about 10,000 RPM (maximum) under a loas of $350 \mathrm{~kg}$ (maximum). Since the speed of rotation is very large, very thin oil is used for lubrication. One of the rollers is rotated by a motor and pulley arrangement $P$. The motor is rated at $1400 \mathrm{RPM}$ and $1 / 4 \mathrm{HP}$. By using the pulley and ' $\mathrm{V}$ ' belt the speed at the roller is increased to 5000 RPM. The bearing mounts $M_{1}$ of the roller $A$ are rigidly fixed to a base $\mathrm{N}$. Cross piece $\mathrm{C}_{1}$ is used to see that the bearings are parallel to each other and there is no strain on the roller. For the same reason the base $\mathbf{N}$ has to be machined carefully to be a flat surface. The other roller $B$ is mounted on bearing mounts $\mathrm{M}_{2}$, which are allowed to move in a cirection perpendicular to the axis of rotation. The cross piece $\mathrm{C}_{2}$ is used to bold the bearings of roller $B$ parallel. The bearing mounts $\mathrm{M}_{3}$ are connected mechanically

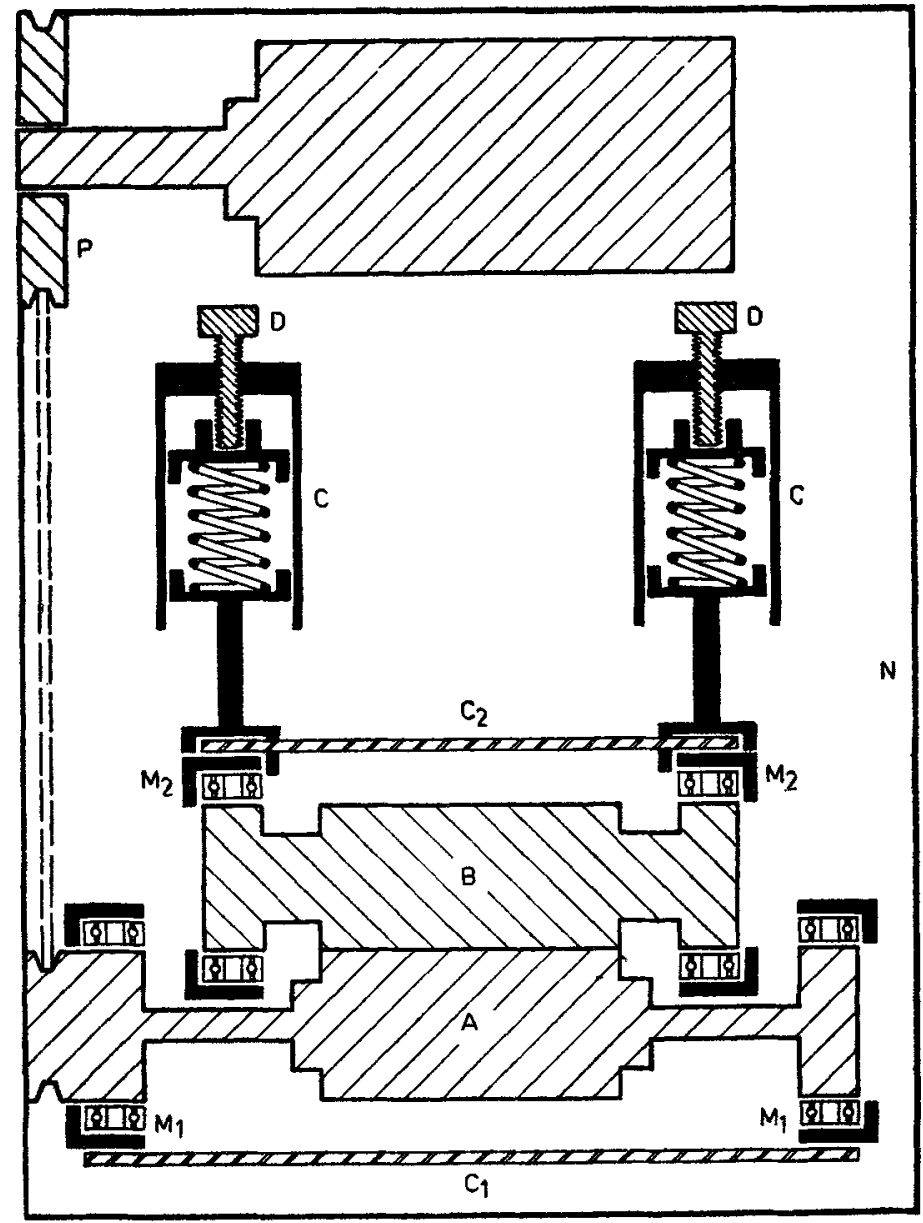

Figure 1. Schematic of rollers. 
to springs $\mathbf{S}$, housed in cylindrical chambers $C$ which are rigidly fixed to the base $\mathrm{N}$. The springs are about $4 \mathrm{~cm}$ in diameter and have a spring constant of $1 \mathrm{~mm}$ per $10 \mathrm{~kg}$ load. When the bolts $D$ are tightened the roller $B$ and the bearing mounts $\mathrm{M}_{2}$ move. Using them, roller $\mathrm{B}$ can be pressed against roller $\mathrm{A}$ with a load of more than $20 \mathrm{~kg}$.

For developing high cooling rates, the molten material is to be rapidly introduced into the rollers so that cooling and oxidation in the atmosphere are avoided. For this the set up shown in figure 2 is used. A furnace $F$ capable of attaining about $1100^{\circ} \mathrm{C}$ is employed. The furnace is well insulated by an asbestos box $\mathrm{A}$. A graphite crucible $C$ is attached to the end of a stainless steel tube T. The crucible has a $1 \mathrm{~mm}$ hole at the other end. There are three springs $S$ at the top. Using them the position of the crucible can be adjusted in the vertical direction as well as in the horizontal plane. The furnace and the crucible arrangement are mounted on a frame so that the crucible can be positioned on top of the rollers. A thermocouple TC is used to determine the temperature and power input to the furnace is varied to change the temperature.

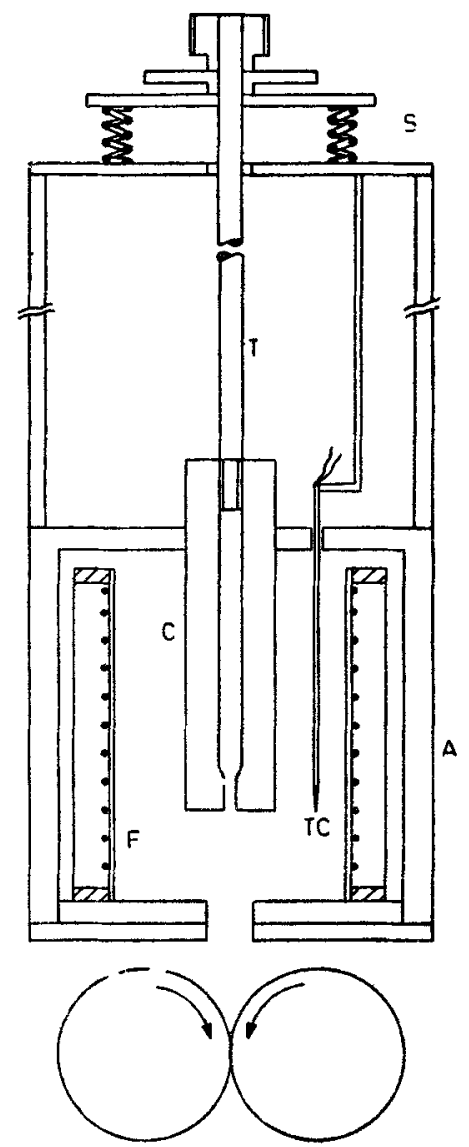

Figure 2. Schematic of furnace and crucible arrangemont. 

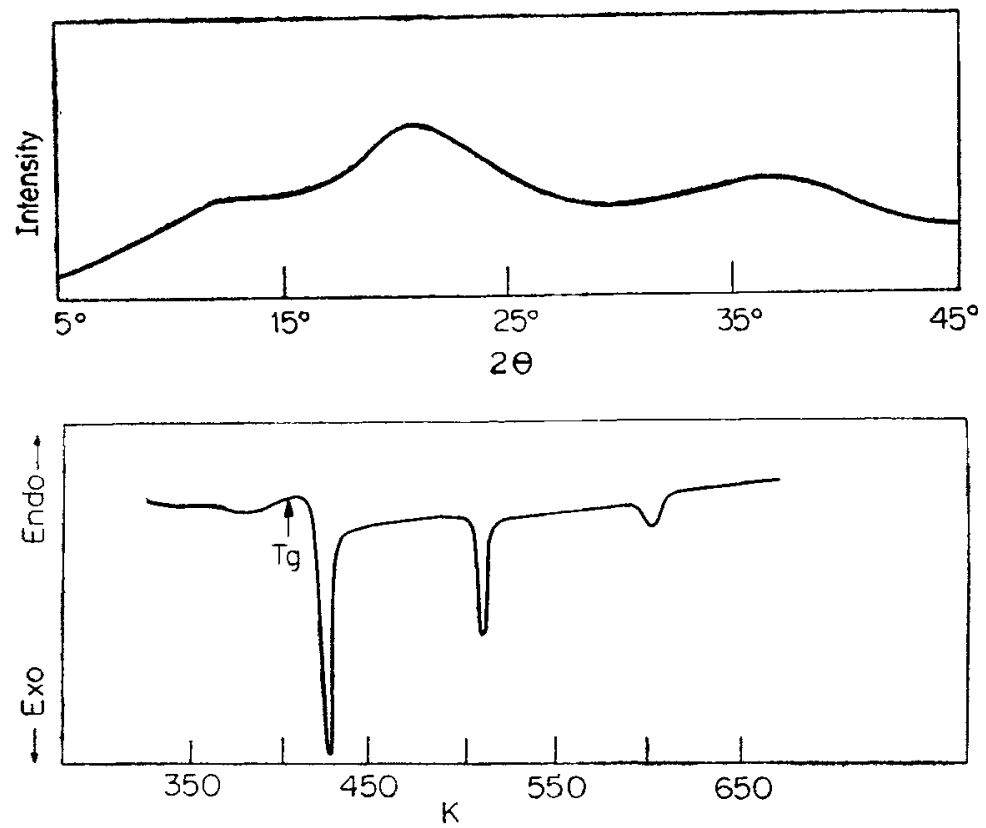

Figure 3. DSC plot and x-ray diffractogram for amorphous $\mathrm{In}_{\mathrm{gg}} \mathrm{Te}_{\mathrm{go}}$ alloy.

\section{Experimental Results}

$\mathrm{Te}_{70} \mathrm{Cu}_{25} \mathrm{Au}_{5}$ and $\mathrm{Te}_{80} \mathrm{In}_{20}$ systems are chosen for testing the apparatus. The alloys are prepared by melting them in evacuated quartz ampules. Both the systems are known to form amorphous phases (Takayama 1976). They are hence useful as test systems for the roller quenching apparatus. A small quantity ( $\sim 50 \mathrm{mg}$ ) of the alloy is introduced into the crucible after it is heated to the required temperature and positioned above the rollers. A small pressure of argon gas (2-3 Atm) is then used and the molten material comes out of the narrow hole in the crucible and falls between the rotating rollers. The foils produced are collected. X-ray investigations and differential scanning colorimetry are used to confirm that the amorphous phases are formed. The DSC plot, shown in figure 3 , clearly shows the endothermic process at the glass transition temperature $\mathrm{T}_{g}$. X-ray diffractometry shows only two broad maxima and the absence of any peaks corresponding to the crystalline alloy. The fact that amorphous phases could be obtained indicate that the system is working properly. The cooling rate produced can be measured by measuring the interdendritic spacing (Chattopadhyay et al 1980). But these are estimates and not accurate measurements. In our system we have not measured the cooling rate. We however note that the alloys $\mathrm{In}_{20} \mathrm{Te}_{80}$ and $\mathrm{Cu}_{25} \mathrm{Au}_{5} \mathrm{Te}_{70}$ were previously produced in amorphous form by Duwez gun technique. It is universally accepted that the Duwez gun produces cooling rates of the order of $10^{6} \mathrm{~K} / \mathrm{sec}$. Since we could produce the same alloys with our system we can state that this set-up produces cooling rates of at least $10^{5} \mathrm{~K} / \mathrm{sec}$. 


\section{Acknowledgements}

We wish to thank Mr K A P Menon, ISRO, Trivandrum and Dr S V Subramanyam and $M r$ P E S Kartha, Department of Physics, Indian Institute of Science, for help in the design and development of the system.

\section{References}

Chen H S and Miller C E 1970 Rev. Sci. Instrum. 4187

Duwez P and Willens R H 1963 Trans. Met. Soc. AIME 227362

Pietrokowski P 1963 Rev. Sci. Instrum. 34445

Pond R, Jun and Maddin R 1969 Trans. Met. Soc. AIME. 2452475

Chattopadhyay K, Ramineni A P and Ramachandra Rao P 1980 J. Mater. Sci. 15797

Takayama S 1976 J. Mater. Sci. 11164 